\title{
Os estágios de aprendizagem de auditores fiscais no contexto da prática profissional
}

\author{
Antonio Soares Neto \\ Governo do Estado da Paraíba \\ Anielson Barbosa da Silva \\ Universidade Federal da Paraíba
}

\begin{abstract}
O artigo identifica os estágios de aprendizagem do auditor fiscal da Secretaria de Estado da Receita da Paraíba no contexto da prática profissional. A crescente demanda social por serviços e agentes públicos mais qualificados torna relevante compreender como se efetiva a aprendizagem profissional desses agentes públicos. O lastro teórico desta pesquisa se situa no campo da aprendizagem organizacional, com ênfase para a aprendizagem contextualizada na ação profissional e para o papel da experiência e da reflexão. A pesquisa se caracteriza como qualitativa, norteada pelo paradigma interpretativo, concebendo-se a realidade como socialmente construída. O método de pesquisa é o da história oral temática. As histórias das experiências e reflexões revelaram que os auditores aprendem inicialmente no curso preparatório, prosseguindo no contexto da prática, no convívio com os auditores veteranos, na vivência de práticas profissionais coletivas, no pertencimento à comunidade de prática, no refletir sobre as práticas, individuais e coletivas, no enfrentamento de situações inéditas, revelando um processo de aprendizagem complexo e dinâmico. Também revelaram que o auditor desempenha "papéis" no processo de sua aprendizagem.
\end{abstract}

Palavras-chave: aprendizagem; auditor; contexto social; prática profissional.

Learning stages from tax auditors in the context of professional practice

The article identifies the learning stages of tax auditors from Revenue State Secretary of Paraíba in the professional practice context. The increasing demand for social services and public servants more qualified, it is important to understand how effective the professional learning of those officials. The theoretical ballast of this research is in the field of organizational learning, with emphasis on contextualized learning in professional action, and the role of experience and reflection. The research is characterized as qualitative, guided by the interpretive paradigm, conceiving of reality as socially constructed. The Oral History is the investigative method. The stories of the experiences and reflections revealed that the auditors initially taught in the preparatory course, continuing in the context

Artigo recebido em 29 dez. 2010 e aceito em 22 jun. 2011.

RAP - Rio de Janeiro 46(3):841-63, maio/jun. 2012 
of practice, the interaction of senior auditors, the collective experience of professional practice, in the belonging in membership in the community of practice, reflect on practices, individual and collective, in facing new situations, revealing a process of learning complex and dynamic. Also revealed that the auditor performs "roles" in his process of learning.

KEY WORDs: learning; auditor; social context; professional practice.

\section{Introdução}

Viver e aprender podem ser considerados conceitos distintos, indissociáveis e complementares (Lindeman, 1926; Teixeira, 1973; Freire, 1996; Senge, 1997; Morin, 2005). As pessoas vivem momentos significativos de suas vidas nas organizações, estando em ininterrupto processo de aprendizagem (Gherardi, Nicolini e Odella, 1998; Smith, 2001; McGill e Brockbank, 2004). A complexidade do ambiente em que agem as organizações ampliou o interesse de acadêmicos, consultores e gestores pela aprendizagem em contexto organizacional (Easterby-Smith e Araújo, 2001).

Buscando situar a aprendizagem, Argyris e Schön (1996) anunciam que tanto ela é um produto (o que se aprende) quanto um processo (como se aprende). Tem sido dada uma ênfase maior ao produto aprendizagem do que ao processo de aprender (Argyris e Schön, 1996).

A notória dificuldade de se investigar empiricamente a aprendizagem também tem conduzido a maioria dos pesquisadores a preferir focar a investigação em seus objetivos e resultados (Easterby-Smith e Araújo, 2001). Tal prevalência já havia sido registrada por Dewey (1959). Prange (2001:49) revela que alguns autores negligenciam "os processos de geração de conhecimento, ou seja, de toda a aprendizagem". Na presente pesquisa, considera-se o aspecto processual da aprendizagem profissional, isto é, atenta-se aos "processos de construção e utilização do conhecimento (perspectiva processual)" (Bitencourt, 2004:60).

A aprendizagem é um conceito indissociável do próprio ato de viver e ocorre também durante o exercício das atividades profissionais, balizada pela aprendizagem social e pelo pensamento reflexivo. Esta pesquisa se alicerça na perspectiva construtivista em que a aprendizagem, por meio da experiência e da prática reflexiva, constitui o processo de formação de conhecimento. Também se recorre à perspectiva da aprendizagem situada, que guarda aspectos conceituais da perspectiva construtivista (Lucena, 2001).

No contexto da ação de um auditor emergem aspectos tais como as relações de aprendizagem com os colegas de trabalho, o encontro da generalidade do saber formal com a especificidade de cada situação real, o desafio das dificuldades práticas profissionais, os momentos reflexivos sobre a própria prática, a construção de um acervo de experiências que auxiliam na caracterização dos estágios de aprendizagem profissional. Aspectos esses que vão contribuir para diferenciar o auditor no início de sua prática, em seus primeiros plantões, e esse mesmo auditor na atualidade. Assim, este artigo objetiva identificar os estágios de aprendizagem de auditores fiscais no contexto da prática profissional com o objetivo de auxiliar na compreensão de um fenômeno complexo. 
A pesquisa encontra eco no crescente interesse pela aprendizagem no ambiente organizacional, por acadêmicos, profissionais, gestores e consultores, demonstrando sua relevância e oportunidade (Easterby-Smith, Burgoyne e Araújo, 2001; Loiola e Bastos, 2003; Bitencourt, 2004).

Considera-se que a compreensão do processo de aprendizagem individual, no contexto das organizações, supre demanda por estudos que enfoquem tal nível, pois a maioria das pesquisas aborda os macroprocessos da aprendizagem organizacional, enquanto diminuta é a produção que trata dos microprocessos dessa aprendizagem (Ruas e Antonello, 2003). Destaca-se, ainda, o esforço em compreender esses processos de aprendizagem, pois "viabilizaria a construção de referências em torno de uma das principais questões acerca da aprendizagem organizacional: o processo de transição do individual para o coletivo" (Ruas e Antonello, 2003:204).

\section{Aprendizagem no contexto da prática profissional}

A faceta da aprendizagem em contexto profissional fora das salas de aula é evento do dia a dia dos profissionais enquanto trabalham em suas organizações, desenvolvendo competências apropriadas, inclusive a competência de aprender a aprender (Gherardi, Nicolini e Odella, 1998; Smith, 2001; McGill e Brockbank, 2004). O crescente interesse pela aprendizagem organizacional é paralelo a uma crescente importância de se perceber a aprendizagem como também gerada na prática social (Elkjaer, 2001). A relevância da aprendizagem situada na convivência social tem sido defendida por pesquisadores e estudiosos da área educacional, parecendo ser este gesto indicativo de se estar reescrevendo a história da aprendizagem (Elkjaer, 2001).

Embora o interesse por tal abordagem seja recente, o fenômeno não o é. Em sua reconstrução histórica da formação do povo brasileiro, Darcy Ribeiro, descrevendo o tipo de processo de aprendizagem vigente nas tribos indígenas, na fase pré-colonial, especificamente na dos tupinambás, relata que "a aprendizagem da convivência e da sobrevivência era feita a partir do modelo dos mais velhos e no fazer e no refazer" (Ribeiro, 2000). Parece possível afirmar que o processo de aprendizagem social precede o de cunho formal. O jornalista Washington Novaes assim destaca as competências do nativo daquele Brasil do século XVI: "sabe fazer a sua casa, sabe fazer a sua roça, planta e colhe, sabe fazer os seus instrumentos de trabalho: seu arco, sua flecha. Sabe fazer esteira, sabe fazer rede e sabe identificar as espécies do seu ambiente que servem como alimento ou como medicamento" (Novaes, 2000).

Nessas passagens, percebe-se a presença de uma aprendizagem contextualizada e socialmente demarcada, buscando-se suprir as demandas pelas competências emergentes da época. Essas descrições de processos de aprendizagem e de saberes coletivamente cultivados remetem ao conceito de aprendizagem que compreende a obtenção de um conjunto de informações socialmente reconhecidas como válidas, por representar o acervo de conhecimento de cada comunidade (Gherardi, Nicolini e Odella, 1998). O indivíduo está situado numa 
condição espaço-temporal, "no sentido em que vive numa época precisa, num lugar preciso, num contexto social e cultural preciso" (Freire, 1979:19). Percebe-se, comparando a realidade indígena acima aludida com a atual do mundo do trabalho, que, se as competências sofreram profundas mudanças, a necessidade de aprender permanece, talvez acrescida da de aprender a aprender. Assim, a natureza humana é marcada pela abertura ao mundo (Berger e Luckmann, 2008)

Aquela realidade indígena bem como a do indivíduo contemporâneo são socialmente construídas, portanto não naturais (Berger e Luckmann, 2008), não sendo possível que um ser humano isolado erija um ambiente humano. O homo sapiens igualmente é homo socius (Berger e Luckmann, 2008:75). Essa natureza social não poderia ser elidida do processo de aprendizagem (Lave e Wenger, 1991; Gherardi, Nicolini e Odella, 1998). Para Lave e Wenger (1991), a aprendizagem de adultos está associada ao contexto social do trabalho, desvelando-se o caráter social da aprendizagem e do conhecimento. Havendo, nesse contexto de trabalho e aprendizagem, relações entre sua história, tecnologia, desenvolvimento das atividades profissionais e relacionamento entre novatos e veteranos (Lave e Wenger, 1991). Elkjaer (2001:106) advoga para essa perspectiva da aprendizagem social a característica de estar "centrada em mudança, em vez de o ser na ordem e regulamentação".

Esse aprender com os pares, no âmbito organizacional, começa quando o profissional novato adentra o seu ambiente de trabalho. Lave e Wenger (1991) cunharam a expressão participação periférica legítima, para designar o processo por meio do qual o profissional principiante se apropria dos saberes necessários à prática profissional, por meio de sua participação social, fazendo jus a dela participar já como profissional pleno.

A aprendizagem também se dá na vida social, quando o indivíduo ao exercer determinada atividade partilha com outros tal momento (Silva, 2009). Lave e Wenger (1991) argumentam que o exercício de atividades e a percepção que seus executores possuem sobre as mesmas são momentos socialmente partilhados, e, dialeticamente, os indivíduos vão concebendo padrões.

Sobre a relação da cognição humana e o contexto social, Morin (2005:18) afirma que as competências do ser humano requerem uma aparelhagem de cognição - o cérebro (máquina de natureza bio-físico-química), que demanda existência biológica humana, e que as atividades cognitivas "só podem desenvolver-se no seio de uma cultura que produziu, conservou, transmitiu uma linguagem, uma lógica, um capital de saberes, critérios de verdade". Destacando o papel do contexto social na formação da cognição humana.

A compreensão da relação entre o meio ambiente e as atividades cognitivas é significativamente ampliada com os estudos da neurociência, que demonstram que os circuitos neuronais pré-programados geneticamente sofrem a influência do ambiente, havendo, portanto, comportamentos cerebrais predeterminados e outros que surgem na medida em que certos genes forem ativados, e não outros, ocasionando a formação de sinapses (conexões entre neurônios) inéditas, possibilitando a ocorrência do fenômeno da aprendizagem (Pereira, 2009). Assim, revela-se o papel do contexto, não só social, nos processos de aprendizagem, na medi- 
da em que a massa cerebral se transmuda para acomodar as informações advindas de novas aprendizagens contextualizadas (Pereira, 2009).

Essa investigação sobre o próprio aprender parece ser pouco frequente entre os profissionais. Kolb (1997) destaca que a gestão da própria aprendizagem tem merecido pouca atenção de gerentes e organizações. Não obstante, o domínio desse processo potencializa o próprio aprendizado, com repercussões nas performances do profissional e da organização.

Também o processo de aprendizagem gerencial pode lançar luz sobre o do profissional, não necessariamente investido da função de comando. Na atualidade, e no contexto de novas competências gerenciais emergentes, Sadler (2001) destaca as de aprender e ensinar. Ruas (2001) advoga haver um gap entre os programas de formação gerencial e o desenvolvimento de competências, talvez indicando a necessidade, na prática dos gerentes e suas organizações, de se vislumbrar o desenvolvimento de competências em outros espaços sociais que não os formalmente constituídos para tal. Nesse sentido, estudos apontam outras vivências de aprendizagem, que não aquelas formalizadas nos programas de formação profissional (Gherardi, Nicolini e Odella, 1998; Lucena, 2001; Hirota e Lantelme, 2005; Silva, 2009).

Para Antonello (2005:205), a aprendizagem situada busca posicionar "pensamento e ação num lugar e tempo específicos". Situar significa envolver indivíduos, o ambiente e as atividades para criar significado, também localizar num setting particular os processos de pensar e fazer utilizados pelos experts para criar conhecimento e habilidades para as atividades (Antonello, 2005). Ação e reflexão figuram como dimensões essenciais dos indivíduos (Dejours, 1991).

Argyris e Schön (1974) destacam que a utilidade dos estudos sobre aprendizagem organizacional está diretamente ligada ao vínculo que se faça entre o pensamento e a ação dos praticantes, como revela a próxima seção.

\subsection{Aprendizagem na ação}

A história da Aprendizagem na Ação tem início com os trabalhos de Reginald W. Revans (McGill e Brockbank, 2004), na década de 1930, por meio da realização de estudos para compreender a dualidade entre o trabalho material e o trabalho intelectivo (Hirota e Lantelme, 2005). Silva (2009:165) a conceitua como "um processo social de gerentes e trabalhadores que atuam em conjunto para revisar, interpretar suas experiências e compreender as situações que os têm levado a solucionar problemas", revelando sua característica de processo contextualizado. McGill e Brockbank (2004) enfatizam o elemento reflexivo dessa aprendizagem, efetivado coletivamente em situações de trabalho.

A experiência pessoal é "pano de fundo" em que se dá a aprendizagem, pois o indivíduo é detentor de capacidade analítica para tratar "informações, dar sentido a elas e encontrar soluções, aprendendo com suas experiências e sendo capaz de formular um pensamento próprio" (Motta e Vasconcelos, 2004:339). O processo de aprender acontece ininterruptamente 
(Robbins, 2005; Demo, 2005). Ainda assim, pode-se afirmar que a maior parte das pessoas não sabe como aprende (Argyris, 1991).

Normalmente, associa-se aprendizagem às instituições formais de ensino, sejam públicas, como as escolas da rede municipal, privadas, como os colégios e cursos preparatórios diversos, ou, mais recentemente, corporativas, como as mantidas pelas organizações para atendimento das necessidades de formação de sua clientela interna. Considera-se o processo educativo como individual, separado do mundo, com duração estabelecida, conhecimentos fragmentados e transmitidos por professores formalmente habilitados (Nicolini, 2007). Nessa concepção, a aprendizagem é vista da ótica de quem ensina. Sendo o "aprender" tido mais como "ser ensinado" (Nicolini, 2007:64). Nessa perspectiva, também conhecida como educação tradicional, o aprendiz é receptáculo carente de conhecimento (sujeito passivo do processo de aprendizagem) a ser suprido por um agente ensinante externo (sujeito ativo do processo de aprendizagem) (Nicolini, 2007).

Diferentemente, a chamada educação nova parte do princípio de que o aprendiz traz consigo os recursos cabais para ser o sujeito de sua própria formação (Nicolini, 2007). Freire (1996) sustenta a tese da antecedência da aprendizagem em face do ensino, sugerindo a prevalência daquela sobre este.

Embora distintas, as aprendizagens formal e informal não são concorrentes. Em espaços formais é possível aprender informalmente, como as dicas permutadas entre os alunos em sala de aula sobre como focar os estudos na véspera de provas; e, em espaços informais, aprender formalmente, como numa fila de agência bancária estudar capítulos de literatura brasileira contemporânea, enquanto se aguarda a vez de ser atendido. Nesse sentido, assim se expressa Nicolini (2007:15):

Conhecimentos situados em um dado contexto podem ser abordados numa escola de preparação técnica para se construir uma teoria geral, num esforço dedutivo, da mesma forma que conhecimentos formais são utilizados como base para situá-los diante dos desafios e características da sua aplicação, de forma indutiva.

Tratando dessa questão, Antonello (2004:2) destaca que se observa na literatura a predominância pela procura de elementos que contraponham essas duas aprendizagens, sendo tal empreendimento equivocado, "pois o mais importante é identificar sua integração".

Conceitualmente, o profissional de qualquer área deve ser capaz de reconhecer um problema, conhecê-lo o suficiente para engendrar solução e aplicá-la, monitorando esse processo (Perrenoud, 2002). A solução é pontual, construção única e contextualizada.

Para Senge e colaboradores (2007:23), "todo aprendizado integra o pensar e o fazer". Sobre o processo de aprendizagem, e alinhado ao pensamento de Senge, Kolb (1997:338) entende que sua natureza é tal que "perspectivas opostas, ação e reflexão, envolvimento concreto e distanciamento analítico, são, todas elas, essenciais para o aprendizado ideal".

McGill e Brockbank (2004) declaram que aprender com a experiência requer reflexão, implicando a revisão de situações passadas, a avaliação das próprias reações, viabilizando 
a concepção de novos procedimentos aplicáveis às situações vindouras. Esse encontro entre reflexão e ação é a base na qual se erige a aprendizagem na ação.

Os pensamentos podem ser classificados como comuns e reflexivos (Dewey, 1959). Pensar é corriqueiramente entendido como fluxo que engloba sonhos, sugestões, ideias desordenadas, desconectadas e, tantas vezes, desconexas. O pensamento reflexivo guarda semelhanças com esse "curso fortuito de coisas através do espírito" (Dewey, 1959:14). No entanto, o faz de forma ordenada e para um objetivo.

Todos refletem sobre o que fazem, profissionais ou não, conscientes da relevância da reflexão ou não. Não só refletir em fazer algo, mas refletir enquanto se faz (Schön, 1998). Dewey (1959) argumenta que pensar reflexivamente difere do simples pensar. O pensamento reflexivo requer o cultivo da dúvida, estimuladora da investigação perfeita, que busca as razões que as justifique, "na qual nenhuma ideia se aceite, nenhuma crença se afirme positivamente, sem que se lhes tenham descoberto as razões justificativas" (Dewey, 1959:25). Dando contornos à sua conceituação, acrescenta que o pensamento reflexivo difere do comum também pela sua ordenação e objetivo. Enquanto no pensamento comum as ideias seguem desordenadas e sem um fim comum, no reflexivo há um ordenamento, uma sequência interdependente e consequente de ideias, geradas e geradoras das mais próximas, resultando num "movimento orientado para um fim comum" (Dewey, 1959:14). Alinhado com essa perspectiva, Perrenoud (2002) diferencia a reflexão episódica do profissional sobre o que faz e a postura reflexiva, esta se configurando em hábito presente nas atividades diárias do profissional.

Freire (1979) argumenta que a reflexão continuada sobre si mesmo e a realidade faz emergir o sujeito plenamente consciente, apto para intervir na realidade para prover mudanças, numa perspectiva emancipatória. Neste sentido, Dewey (1959:96) declara que a "verdadeira liberdade, em suma, é intelectual. (...). Cultivar a atividade exterior irreflexiva e sem peias é favorecer a escravidão, pois a pessoa assim educada fica à mercê de seus apetites, de seus sentidos e das influências exteriores".

O pensamento reflexivo parte de uma situação pré-reflexiva incômoda e se completa numa situação pós-reflexiva resolvida. Numa reconstrução do saber estabelecido. "Em suma, o verdadeiro pensar termina por uma apreciação de novos valores” (Dewey, 1959:106).

Reynolds (1998) declara que a reflexão é a essência do processo de aprendizagem, especialmente ao considerar a aprendizagem como desenvolvimento. Nessa perspectiva, Elkjaer (2001:113) entende que uma pessoa aprende "somente quando é capaz de refletir sobre suas ações e reorganizar, assim como reconstruir experiência, por meio de um processo contínuo de reflexão - pensamento - como um meio de atuação".

Freire (1979) defende uma reflexão que preceda toda a ação educativa, e que pondere sobre o ser humano e seu contexto de vida concreto, no intuito de evitar que o sujeito se sujeite à condição de objeto da educação. Senge e colaboradores (2007) declaram que o pensar e o fazer são elementos integrantes da aprendizagem. Mintzberg e Gosling (2003:32) celebram o encontro da reflexão e da experiência, no qual germina a aprendizagem, que ocorre "quando os conceitos encontram as experiências por meio das reflexões". 
Portanto, refletir é agir, intelectualmente. As situações vivenciadas, as reações tidas, os resultados obtidos e o contexto formam o conjunto da ação prática, que passa a condição de objeto de atenção da reflexão. Num esforço compreensivo de um acontecimento, o profissional desconstrói a ocorrência em componentes menores, para melhor análise e compreensão, depois a reconstrói, atribuindo-lhe novo perfil, e a experiência agora ganha adjetivo, é experiência refletida. Quando socializada, permite novas, convergentes e divergentes reflexões, ensejando a arquitetura de mais novas abordagens. A ação individual passa a ser percebida dentro de parâmetros holísticos (Preskill e Torres, 2001).

Nos estudos sobre aprendizagem organizacional, a aprendizagem por meio da "experiência é um componente genuíno de quase todas as abordagens" (Prange, 2001:49), indicando a relevância da experiência nos processos de aprendizagem. A experiência é fruto da interação entre o sujeito e tudo que o rodeia, sendo, portanto, acontecimento cotidiano (Dewey, 1974). Tudo que rodeia o indivíduo pode ser entendido como a multiplicidade de elementos que se relacionam em arranjos infindos (Teixeira, 1973).

Freire (1996:49), sustentando a importância das experiências individuais para a educação, declara a relevância "das experiências informais nas ruas, nas praças, no trabalho, nas salas de aula das escolas". Para Reynolds (1998), a reflexão tem papel integrador entre a prática e o conhecimento, constituindo um processo de aprendizagem. Mesmo as experiências malsucedidas carregam em si elementos para uma reflexão instigadora para o desenvolvimento. "Não existe melhor pedra de toque para a capacidade de pensamento do que o uso que se faz dos próprios enganos e erros" (Dewey, 1959:118).

A aprendizagem não está circunscrita apenas aos ambientes formais de educação. No mundo do trabalho, o profissional iniciante se percebe em realidade não totalmente conhecida, não plenamente atendida pelas noções teóricas de sua formação profissional. Com as primeiras práticas, ingressa não só nas atividades cotidianas de sua profissão, como também na comunidade de profissionais da qual passa a ser membro. As situações de trabalho, o convívio com os pares, a socialização de experiências, de incertezas, de interpretações vão se constituindo em estágios de aprendizagem. Ação e reflexão se sucedem, confundem-se e se fundem, ensejando aprendizagens. Vida e aprendizagem surgem como conceitos irmanados, em realidades contextualizadas, indicando se tratarem de fenômenos universais, com características situadas.

\section{Metodologia}

O artigo é resultado de uma pesquisa empírica, com abordagem qualitativa e narrativa, mediante o uso da história oral temática. A opção pela abordagem qualitativa se fundamenta na convicção de haver "uma relação dinâmica entre o mundo real, objetivo, concreto e o sujeito" (Oliveira, 2005:68). O caráter descritivo permite o registro das opiniões dos entrevistados, capturando suas percepções sobre aspectos gerais ou específicos de um determinado contexto social (Oliveira, 2005). A escolha da história oral como método de pesquisa se apoia no 
enfoque social da aprendizagem nesta pesquisa, considerando-se o crescente fortalecimento dessa perspectiva (Easterby-Smith e Araújo, 2001). É crescente a percepção da relevância do método da história oral nos estudos organizacionais (Ichikawa e Santos, 2006; Closs e Antonello, 2008). Tendo-se as histórias por portadoras da memória organizacional, "seu desenvolvimento constitui aprendizagem organizacional” (Sims, 2001:79). Gonçalves e Lisboa (2007) atestam que a fonte oral se apresenta como base primeira para a aquisição de conhecimento, científico ou não.

O método da história oral possui dois momentos dependentes e inter-relacionados. O primeiro é o da captação e registro da memória que se quer estudar, por meio de entrevista, estando definidos os entrevistados e o objeto da entrevista. O outro momento é o da análise dialética do material obtido (Bretas, 2000). O método se apresenta em três formas: história oral de vida, por meio da qual o narrador relata sua trajetória de vida ao longo do tempo; a tradição oral, pela qual o depoente discorre sobre determinados momentos que ele vivenciou, presenciou; e a história oral temática, na qual o participante foca sua narrativa num aspecto de sua vida (Bretas, 2000). Empregou-se essa última modalidade, enfocando-se a temática da aprendizagem de sujeitos no contexto da ação profissional.

O contexto da pesquisa é a Secretaria de Estado da Receita da Paraíba, e o sujeito é o auditor fiscal tributário estadual, que inicia suas atividades no âmbito da fiscalização de mercadorias em trânsito, prioritariamente, conforme estabelecido em lei (Paraíba, 2007).

A escolha dos entrevistados ficou condicionada à disponibilidade e ao interesse demonstrado pelos mesmos (Gorden apud Rosa e Arnoldi, 2009), bem como pela relação de confiança existente com o pesquisador (Thompson, 2002).

As narrativas das experiências foram obtidas mediante entrevista semiestruturada. Optou-se pela utilização, adaptada, do método de entrevista em profundidade apresentado por Seidman (1997). Na proposta de Seidman, neste tipo de pesquisa não se trabalha com um número rígido de questões, a intenção é despertar a memória dos entrevistados acerca de tópicos que se deseja estudar.

A proposta de Seidman (1997) prevê a realização de três entrevistas. Na primeira, busca-se que o entrevistado conte o máximo sobre o assunto em pauta. Na segunda, concentra-se nos detalhes dessa experiência, buscando-se nas narrativas as percepções do entrevistado. Na terceira, procura-se que o entrevistado reflita sobre suas experiências. Neste estudo, foi realizada uma adaptação desse método, fundindo a primeira e a segunda entrevistas em uma só, concluindo o ciclo de duas entrevistas focalizando o caráter reflexivo desse modelo.

As entrevistas foram realizadas entre outubro e novembro de 2009 com 10 auditores fiscais, sendo cinco ingressantes no serviço público no concurso realizado em 1994 e os outros cinco ingressantes no ano de 2006. No primeiro contato com cada auditor, efetuado no contexto de trabalho, foi apresentado o projeto de pesquisa e foram acordadas as condições de processamento das mesmas, assegurando-se a omissão de dados que pudessem identificá-los, por não serem relevantes para a pesquisa e em atendimento a uma característica própria de algumas áreas profissionais, "cuja ética de trabalho dá grande ênfase à confidencialidade e ao segredo, tais como funcionários públicos, e gerentes de banco" (Thompson, 2002:264). 
Após a transcrição das entrevistas, iniciou-se, formalmente, a análise dos dados. Formalmente, pois parece impossível evitar a tentativa de compreensão dos dados, ainda que em forma embrionária, nas fases iniciais da pesquisa. Minayo (2003) defende que já na fase de coleta de dados o processo de análise pode ter se iniciado. A análise de dados é composta por três ações distintas e integradas: descrever, classificar e estabelecer conexão (Silva, 2005). Silva (2005:82), detalhando esses três momentos e o funcionamento do processo, destaca que a análise deve conter descrições compreensivas sobre o contexto da ação, as intenções do sujeito e sobre o processo no qual a ação se desenvolve. Em seguida, os dados são agrupados em temas. Ao fim, procede-se à análise dos mesmos, em busca de conexões e significações.

Na medida em que as histórias eram contadas, podiam-se perceber tópicos recorrentes, correlações possíveis. A "arrumação" final das narrativas se deu após várias leituras e audição das gravações, que guardam a emoção da linguagem falada, tantas vezes reveladora de significados que a palavra escrita não consegue transmitir (Thompson, 2002; Freitas, 2006; Alberti, 2007). Nesse sentido, Alberti (2007) argumenta que, embora as narrativas individuais constituam a unidade de análise da história oral, cabe ao pesquisador o papel de revelar as relações possíveis entre narrativas, transcendendo seu caráter particular, revelando suas contribuições para a compreensão de fenômenos sociais.

As histórias narradas representam reconstruções de momentos vividos por esses profissionais em sua aprendizagem no contexto da ação profissional. Neste artigo, a intenção é identificar os estágios de aprendizagem dos auditores fiscais. Em cada estágio, apresenta-se a análise compreensiva interpretativa dos significados, utilizando narrativas dos auditores sobre sua aprendizagem. Essas narrativas, à luz do referencial teórico contemplado, permitiram a reconstrução das mesmas, agora desveladas, da perspectiva da aprendizagem em contexto da prática profissional.

\section{Resultados da pesquisa}

Foram reconstruídas pelos auditores fiscais, via história oral e tendo por foco a aprendizagem, a fase de preparação para o concurso público e a participação no curso de formação, os primeiros plantões com as primeiras práticas, o ingresso na comunidade de prática, as interações sociais com os outros colegas e a experiência de recepcionar um novato.

Da pesquisa emergiram estágios relevantes da aprendizagem do auditor, nos quais o auditor desempenha "papéis" específicos situados no momento de sua aprendizagem e contextualizados de maneira particular com a comunidade de prática de auditores fiscais. A seguir, esses "papéis" são apresentados e descritos como estágios presentes na aprendizagem do auditor. Cada estágio indica o processo, a experiência, o cenário e o momento da aprendizagem. Para ilustrar os significados de cada estágio, apresentam-se trechos selecionados das entrevistas, com o objetivo de tornar o leitor partícipe dessa discussão, na medida em que "ouve" as histórias, ainda que em recortes, contadas pelos auditores fiscais. 


\subsection{Aprendiz formal}

Neste estágio, o auditor recém-contratado é discente num processo formal de educação profissional. O Curso de Formação para Auditores, ministrado em sala de aula e visitas a postos fiscais (ambiente de trabalho) pela Escola de Administração Tributária (Esat), surge como momento relevante para a aprendizagem que se efetivará na prática profissional. Os entrevistados revelam sua importância para a prática, e mesmo as críticas que surgem nascem a partir do conhecimento formal, ministrado no próprio curso. Essas críticas, que o curso não prepararia totalmente o aprendiz para as situações da prática, parecem se referir menos à qualidade do curso e mais a uma aprendizagem inseparável da prática profissional, do fazer cotidiano. Essa aprendizagem inalienável da ação tem início com os primeiros plantões.

O Curso de Formação eu achei muito válido, assim podem criticar, mas eu achei muito válido mesmo. Mas, tem alguma coisa ou outra que você quando vai para praticar é que você tem dúvida. (Auditor 1)

O entrevistado percebe como válido o curso, também reconhecendo que há quem o critique. Revela que há aspectos na prática que fazem emergir a dúvida. Já outro entrevistado relata que a prática foi precedida por visitas a Postos Fiscais (as "praticasinhas"), constantes do programa do curso. Nessas ocasiões, os formandos mantinham contato direto com situações que iriam vivenciar na prática, posteriormente. Esses momentos facilitaram os primeiros plantões, nas palavras do entrevistado "não ficou tão assim, não", ou seja, contribuíram para o desempenho das funções pelo auditor novato, naqueles primeiros dias.

Primeiro plantão a gente ficou... "rodando"... (no comando fiscal). Chegava, eu e meu colega, a gente ficava... pra conhecer. O primeiro plantão ficamos mais pra reconhecimento de área. Depois eu fui para o interior. A gente foi pro Comando. Como era muita gente, você ficava mais disperso dentro da multidão... Mas, era abordando (fiscalizando veículos que transportavam mercadorias). Aí, depois, eu fui para o Posto Fiscal de (...). A gente teve umas... "praticasinhas", (...) no Posto Fiscal de (...), nos dias em que a gente veio conhecer (durante o Curso de Formação), então não ficou... tão assim, não. Inclusive acho que o curso deveria ter mais tempo disso aí (as práticas). Devia se tornar alguma coisa mais certa, foi muito rápido. Não sei exatamente quanto tempo levou. Mas, sei que foi muito breve em relação ao resto do curso. Porque você fica ali vendo Garantido, ${ }^{1}$ e não sei o quê. Mas, se chega, olha a nota, olha o sistema, se torna mais prático. Na realidade, mais real, mais palpável. (Auditor 6).

As primeiras impressões sobre a prática, dúvidas que surgem, situações embaraçosas, conselhos que se estejam precisando serão partilhados entre esses colegas da "primeira hora".

\footnotetext{
${ }^{1}$ Imposto sobre Circulação de Mercadorias/PB incidente sobre a comercialização de certos produtos.
} 
Os auditores veteranos exerceram papel relevante nos primeiros plantões, nas situações iniciais da prática.

\subsection{Observador da prática}

O auditor novato vivencia as primeiras práticas profissionais acompanhado de um auditor veterano, empenhado em colaborar na aprendizagem do ingressante. Para o auditor novato a presença de um colega veterano é fundamental para ajudá-lo a se apropriar mais rapidamente dos procedimentos adotados na prática fiscal, diante de situações reais. $\mathrm{O}$ novato observa $\mathrm{o}$ veterano em ação.

Em função do próprio contexto de trabalho, normalmente as atividades são desenvolvidas por, ao menos, dois auditores. Essa companhia veterana é interpretada como sendo benéfica, fundamental mesmo, nesse período inicial. Observando o veterano, o novato se aproxima da prática, fazendo conexões entre o conhecimento formal, do Curso de Formação, e a ação profissional, das situações reais.

Ah, eu tive ótimos mestres. Colegas com muita paciência para me explicar tudo. Então eu acho que os fiscais que estavam aqui, realmente são as pessoas mais importantes para quem está começando. (...). Então, eu acho que primeiro você deve pegar pessoas antigas na Casa para ajudar. Assim, no começo para conferir um caminhão, eu queria saber qual o procedimento, como você tinha que lidar com o motorista. Então, eu observava... eu pedia para o fiscal veterano ir lá para eu ver como é que era que fazia. Eu observava muito no começo. No começo, na transição da noite, eu não queria ficar só, então eles realmente não me deixavam. Então, a partir do quarto plantão é que eu comecei a ficar só, na noite. Assim, não foi muito pavoroso por isso, porque os "meninos" tinham muita paciência comigo. Assim, quando você aprende, você não sabe como no Sistema (Sistema Átomo) você autua, então eles iam ensinando. Então, eu não tive muito stress por isso. (Auditor 1)

Da fala é possível extrair que o conhecimento do veterano e sua habilidade foram relevantes para o aprendizado profissional do novato. Mas outro componente é revelado. A atitude de querer ensinar, de guiar o novato, do auditor veterano. Como exemplo, a paciência "para explicar tudo". Também necessária para ir "ensinando", como processo de ensino e aprendizagem que se efetua no transcurso do tempo.

\subsection{Praticante observado}

Neste estágio, o auditor novato se percebe observado pelo veterano, invertendo-se as posições de observado e observador. Ao começar a solucionar situações reais do trabalho de fiscalização, dominando alguns procedimentos, o auditor novato se percebe um auditor, na prática, sendo também assim reconhecido pela comunidade de prática. Os auditores veteranos, cole- 
gas de plantão, percebem pela observação que o "novato" passa a dominar procedimentos e solucionar questões reais, com desenvoltura e independência.

É... eu notei. Poucos plantões depois, quando você já começava a dominar aquelas situações que você abordava. Quando você já sabia o que fazer. Os outros automaticamente passaram a lhe aceitar como um do meio. Você também saber entrar naquele meio. (Auditor 3)

O auditor novato, embora não possua experiência, não está desprovido da curiosidade (talvez necessidade) de conhecer o contexto em que passa a atuar. Mesmo na observação de como se proceder na prática, o novato reivindica explicações que exponham as razões para cada ação da prática. A realidade é inteligível, sujeitando-se a ser objeto cognoscível do sujeito cognoscente (Freire, 1996; Demo, 2005). A fala abaixo retrata essa necessidade.

Assim a abertura que o colega permite que você vá e o aborde, isso tudo facilita. E no início não acontecia isso. A pessoa tomava todas as decisões. "Vamos ver isso aqui hoje. Vamos pra tal lugar." E aí abordava o carro, e não explicava por que estava fazendo aquilo, o que é que ele tava pensando. "Oh, aqui porque aqui geralmente pinta uma determinada situação" e criava um clima ruim. "Ele é o sabe-tudo e eu tenho que ficar quieto, só olhando para aprender". (Auditor 10)

Esses relatos sugerem um acompanhamento do auditor novato, em seus primeiros plantões, bem como que o auditor sênior parceiro atenda a determinados requisitos. Como a vontade de colaborar no processo de aprendizagem do auditor novato, noções de aprendizagem de adultos e de aprendizagem na prática, entre outras pertinentes. Ilustrando um processo de apreensão de significados, a partir do momento em que o auditor é legitimado por um veterano que o auxilia a aprender a prática profissional. A comunidade de auditores já participa desse processo de aprendizagem, pois é responsável pela recepção do novato e condução da complementação de sua formação, agora na prática.

\subsection{Praticante reflexivo}

O processo de aprendizagem que teve início com o Curso de Formação prossegue com as aprendizagens advindas da prática, que se enriquecem com as reflexões decorrentes desse praticar a teoria. Sua própria prática e a prática hegemônica na comunidade serão objeto de reflexão do auditor. Como resultante deste esforço de síntese, ter-se-ão novos padrões de ação fiscal, tanto individual, quanto coletivamente, uma vez que o processo entre auditor e sua comunidade de prática é crítico, dialético e permanente.

Às vezes você age de determinada maneira e é bom você refletir pra ver o que você fez que poderia ser melhorado. (...) em algumas situações eu ajo de uma determinada maneira, e assim eu reflito para que eu realmente mude aquele ponto. (Auditor 2) 
A reflexão, própria do humano (Dewey, 1959; Freire, 1996), permite ao sujeito o estar no mundo de forma crítica, autocrítica, transformadora, autotransformadora. O propósito é refletir e mudar, se for o caso, para melhor.

Olha se não ficou pendência, se não houve problema no plantão, foi um plantão normal. Agora se houve de fato algum problema, algum aborrecimento, aí tem hora que vêm aqueles flashes. Você vai pensar o que é que houve para que acontecesse aquilo? Volta nesse momento, quando há alguma anormalidade. Você lavrou um auto de infração, teve um atrito com um motorista, só nesses casos mesmo. Ou, se determinada situação gerou uma dúvida, aí você começa a refletir pra pesquisar, correr atrás. (...) Justamente pra evitar que o fato venha a se repetir. É uma situação nova, que não saiu como planejado, que a gente vai pesquisar, procurar corrigir as falhas pra não acontecer mais. (Auditor 5)

Esse pensamento reflexivo pode surgir de maneira genérica ou preventiva, como parece sugerir o relato do Auditor 8, que revela refletir sobre aspectos do cotidiano da prática, que possivelmente irão constar no plantão seguinte. Sua experiência da prática elenca algumas situações comuns de trabalho, e com essa "tela" projetada em seu pensamento ele avalia "passos", "atitudes", "comportamentos". E neste exercício mental encontra "um processo de amadurecimento".

Na noite anterior, eu sempre penso. A gente pensa no plantão do dia seguinte, sempre. Você vai dormir pensando no horário. Chegar, se vai ser tumultuado, se vai ser um plantão mais tranquilo, a gente pensa sim, normalmente, ou quase sempre. (...) Você reflete, talvez você esteja refazendo alguns passos, algumas atitudes, alguns comportamentos. Você tá trabalhando, é um processo de amadurecimento também. É um preparo para o plantão. (Auditor 8)

\subsection{Praticante ouvidor e contador de histórias}

Integrando o ambiente de aprendizagem na prática está a socialização das situações reais vivenciadas. Essas vivências relatadas coletivamente passam a figurar como histórias vinculadas à comunidade de prática, delineando seu perfil (Lave e Wenger, 1991). Esses diálogos profissionais estabelecem novos parâmetros de trabalho, corroboram antigos ou os modificam. Essas socializações de histórias ocorrem no contexto de trabalho, postos fiscais e, fora dele, no veículo utilizado para o percurso casa-posto fiscal-casa, feito em grupo, em momentos de lazer.

Quando a gente vai fazer uma ação fora, a gente conta como foi a estratégia. Enriquece muito nosso comportamento para o próximo auto (de infração). Às vezes, no carro a gente vai pra casa conversando ainda sobre trabalho. E, quando a gente debate o que aconteceu, onde é que a gente podia ter melhorado, a gente nota que no auto de infração seguinte já sai quase que automático. Parece que as pessoas absorvem e intimamente ficam mais preparadas (Auditor 3). 
As experiências partilhadas "fazem amadurecer", não são apenas faladas e ouvidas, são maturadas ou refletidas. O aprendizado daí advindo passa a compor o acervo individual e do grupo. Por meio do diálogo, da linguagem, experiências de trabalho são narradas, analisadas e refletidas. Nesse sentido, Gherardi, Nicolini e Odella (1998:274) argumentam que "em organizações de trabalho, pessoas e grupos criam conhecimento, negociando significado de palavras, ações, situações e artefatos materiais". Os auditores buscam coletivamente construir novos parâmetros de trabalho a partir dos parâmetros existentes que, por motivos que são investigados coletivamente, não mais apresentam os resultados esperados. A narrativa a seguir ilustra essa peculiaridade dos diálogos de trabalho efetivados nos postos fiscais, durante os plantões, e nos veículos dos auditores, quando retornam aos seus lares após um plantão, utilizando-se do transporte solidário.

Sempre que eu saio do plantão, como a gente vem de carona, vem junto, nesse plantão que eu tô. Sempre eu procuro ver as coisas que foram mais marcantes, e tentar passar para os outros. Porque nem sempre os colegas estão na hora. Às vezes, um está indo atrás de um carro, fazendo uma diligência. Então, como nem sempre todos estão naquele momento, então eu acho interessante fazer uma interação do serviço para que as dúvidas sejam sanadas. Sempre no trajeto, justamente para casa, é o período que eu faço essa retrospectiva. Agora, depois em casa, não. (Auditor 2)

Determinadas situações são narradas, em retrospectiva, buscando-se conhecer e analisar o contexto em que ocorreram. Também as ações dos auditores que nelas atuaram são contadas, os pressupostos que originaram suas ações igualmente são expostos para o grupo, que passa a analisar toda a situação e seu desfecho. Essas novas situações igualmente passarão pelo mesmo processo coletivo de aprendizagem. Tal situação encontra guarida nos estudos de Gherardi, Nicolini e Odella (1998), que apontam que o conhecimento não está dentro da cabeça dos indivíduos, nos livros ou armazenado em banco de dados. Para esses autores, conhecer é "ser capaz de participar com os requisitos de competência em uma rede complexa de relacionamentos entre pessoas e atividades" (Gherardi, Nicolini e Odella, 1998:274).

\subsection{Praticante reflexivo coletivo}

Os auditores conjuntamente refletem sobre as histórias de suas práticas profissionais, naqueles mesmos ambientes em que essas histórias são socializadas. Como fruto dessa reflexão coletiva surgem os procedimentos de trabalho validados pelo grupo, as crenças reinantes, as interpretações hegemônicas. No entanto, se esses momentos tecem paradigmas de trabalho, também os modificam ou os substituem.

Ao se deslocarem para o trabalho ou voltarem para suas casas, os auditores que se utilizam do transporte solidário (um grupo no mesmo veículo) aproveitam esses momentos para relatarem casos vividos, pormenores relevantes, atitude experimentada, reação produzida, desfecho da situação, entre outros ricos aspectos da prática. A conversa descontraída, 
pós-plantão, contribui na formação do profissional e sedimenta a comunidade de prática dos auditores fiscais que atuam nos postos fiscais. Enfatiza-se, assim, uma das características da aprendizagem na ação, a de ser uma experiência coletiva, pela qual toda a aprendizagem e desenvolvimento ocorrem por meio do diálogo entre os pares (McGill e Brockbank, 2004).

Normalmente, sim, sim. Alguma coisa sim. Quase todos os plantões, quando a gente sai, a gente tem uma discussão daquilo que foi processado, da rotina do trabalho. Nós saímos com os colegas... sempre há algum comentário em relação a alguma coisa que aconteceu durante o plantão. Isso ai é a praxe. (...) De qualquer maneira, agrega alguma coisa, algum conhecimento. Porque você quando estabelece esse processo de discussão sempre fica alguma coisa, sempre soma, é experiência a mais. Quando você ouve o outro isso já é um processo de aprendizado. (...) Sempre soma, sempre são experiências. Sempre vai agregar experiências. Sempre esses incidentes, alguns entreveros, talvez, mas somam porque você amadurece. Você vai aprendendo, e em outra situação que você se deparar, você já refletiu em cima daquilo e você vai moldando seu comportamento. (Auditor 8)

O relato do auditor aponta a adoção de um "procedimento" de aprendizagem espontâneo, o espaço do veículo no qual os auditores se deslocam para o Posto e deste para suas residências é ambiente de aprendizagem. Essa troca de experiências entre os auditores é traço característico de uma comunidade de prática (Lave e Wenger, 1991) e é percebida como relevante para o processo de aprendizagem de como ser auditor fiscal.

\subsection{Praticante docente da ação}

Neste estágio, o outrora novato auditor está plenamente imerso na comunidade de prática de auditores fiscais. As experiências e reflexões contextualizadas na prática forjam sua aprendizagem profissional no contexto da prática, ao ponto de o mesmo se perceber capaz de ensinar, a um auditor novato, o que ele aprendeu enquanto agia.

Recebi um novato para trabalhar (...) Então, eu passei pra ele a coisa na prática, aquilo que eu já tinha vivenciado. E, compartilhando também com ele. Passei apenas um pouco de experiência prática pra ele, ensinar os caminhos, ensinar os procedimentos, aonde e como começar, de que maneira abordar em determinados casos. Uma coisa que a gente vai aprendendo com a prática... (Auditor 4)

As características do trabalho, como o regime de plantão de 24 horas, o deslocamento casa-trabalho-casa feito em grupo, o trabalho em equipe, o pertencer a uma comunidade de prática, a análise de cada situação da prática em face da legislação pertinente, o julgamento das considerações apresentadas pelos contribuintes, a atividade percebida como estressante compõem o contexto no qual o auditor trabalha e aprende a trabalhar. 
A pesquisa revelou uma aprendizagem situada no contexto da prática profissional, que surge no decurso da ação e imersa na cultura local. A interação social é elemento constituinte dessa aprendizagem, mas também representa elemento participante da constituição da comunidade de profissionais que a integram (Lave e Wenger, 1991).

Existe um conjunto de oportunidades de aprendizagem na ação que o novato encontra quando ingressa numa dada comunidade de prática (Gherardi, Nicolini e Odella, 1998). Para o auditor novato, observar as práticas dos auditores veteranos representa um aspecto determinante em sua aprendizagem na ação. Outro elemento é sua relação com os pares, manifestada pelo diálogo em torno de uma situação de trabalho, pela socialização das experiências e reflexões sobre a prática profissional, pela declaração de dúvidas com relação à resolução de situações práticas, interpretação da legislação e pelo delineamento de uma situação problemática e seu respectivo enquadramento legal.

\section{Conclusão}

A fundamentação teórica, como base de conhecimento, a utilização da história oral temática, como método de pesquisa, as histórias que os auditores contaram, como relatos da realidade prática, a interpretação dessas histórias, como compreensões de uma realidade, e o pensamento reflexivo do pesquisador, como gestor desses elementos da pesquisa, possibilitaram a identificação dos estágios de aprendizagem do auditor fiscal, assim como dos elementos da aprendizagem (processo, a experiência, o cenário e o momento).

Da pesquisa emergiram estágios da aprendizagem, contextualizados de maneira particular com a comunidade de prática de auditores, conforme síntese a seguir.

$$
\text { Quadro }
$$

\section{Aprendizagem do auditor fiscal no contexto da prática profissional}

\begin{tabular}{|c|c|c|c|c|}
\hline $\begin{array}{l}\text { Estágios de } \\
\text { Aprendizagem } \\
\text { do Auditor }\end{array}$ & $\begin{array}{c}\text { Processo de } \\
\text { Aprendizagem }\end{array}$ & $\begin{array}{l}\text { Experiência da } \\
\text { Aprendizagem }\end{array}$ & $\begin{array}{c}\text { Cenário da } \\
\text { Aprendizagem }\end{array}$ & $\begin{array}{c}\text { Momento de } \\
\text { Aprendizagem }\end{array}$ \\
\hline Aprendiz formal & Educação formal & $\begin{array}{l}\text { Participação no Curso } \\
\text { de Formação }\end{array}$ & $\begin{array}{l}\text { Salas de aula e visitas } \\
\text { aos postos fiscais }\end{array}$ & $\begin{array}{c}\text { Curso de Formação para } \\
\text { Auditores }\end{array}$ \\
\hline $\begin{array}{l}\text { Observador da } \\
\text { prática }\end{array}$ & $\begin{array}{l}\text { Observação dos } \\
\text { veteranos em ação }\end{array}$ & $\begin{array}{c}\text { Percepção dos padrões } \\
\text { de ação usados na } \\
\text { prática }\end{array}$ & $\begin{array}{l}\text { Situações de prática, nas } \\
\text { quais o veterano age }\end{array}$ & $\begin{array}{l}\text { Primeiros plantões. } \\
\text { Situações inéditas }\end{array}$ \\
\hline $\begin{array}{l}\text { Praticante } \\
\text { observado }\end{array}$ & $\begin{array}{c}\text { Prática profissional } \\
\text { mediada pela orientação } \\
\text { de um auditor experiente }\end{array}$ & $\begin{array}{c}\text { Vivência dos padrões } \\
\text { de ação }\end{array}$ & $\begin{array}{c}\text { Situações práticas, } \\
\text { nas quais age, e é } \\
\text { acompanhado por } \\
\text { veterano }\end{array}$ & $\begin{array}{l}\text { Situações cotidianas. } \\
\text { Processo de legitimação } \\
\text { como membro da } \\
\text { comunidade }\end{array}$ \\
\hline $\begin{array}{l}\text { Praticante } \\
\text { reflexivo }\end{array}$ & $\begin{array}{c}\text { Ação e reflexão sobre sua } \\
\text { prática profissional }\end{array}$ & $\begin{array}{l}\text { Reflexão na prática dos } \\
\text { padrões de ação }\end{array}$ & Situações práticas & $\begin{array}{c}\text { Após as ações, } \\
\text { quando reflete em sua } \\
\text { performance }\end{array}$ \\
\hline
\end{tabular}

Continua 


\begin{tabular}{|c|c|c|c|c|}
\hline $\begin{array}{l}\text { Estágios de } \\
\text { Aprendizagem } \\
\text { do Auditor }\end{array}$ & $\begin{array}{l}\text { Processo de } \\
\text { Aprendizagem }\end{array}$ & $\begin{array}{l}\text { Experiência da } \\
\text { Aprendizagem }\end{array}$ & $\begin{array}{l}\text { Cenário da } \\
\text { Aprendizagem }\end{array}$ & $\begin{array}{l}\text { Momento de } \\
\text { Aprendizagem }\end{array}$ \\
\hline $\begin{array}{l}\text { Praticante } \\
\text { ouvidor e } \\
\text { contador de } \\
\text { histórias }\end{array}$ & $\begin{array}{c}\text { Troca de experiências } \\
\text { (conta e ouve histórias } \\
\text { sobre a prática com seus } \\
\text { pares) }\end{array}$ & $\begin{array}{l}\text { Vivência da dimensão } \\
\text { social da aprendizagem }\end{array}$ & $\begin{array}{c}\text { Carona solidária, } \\
\text { encontros sociais, } \\
\text { ambiente dos plantões }\end{array}$ & $\begin{array}{c}\text { Ao longo da carreira } \\
\text { fiscal }\end{array}$ \\
\hline $\begin{array}{l}\text { Praticante } \\
\text { reflexivo coletivo }\end{array}$ & $\begin{array}{l}\text { Reflexão coletiva sobre a } \\
\text { prática profissional }\end{array}$ & $\begin{array}{l}\text { Vivência da dimensão } \\
\text { social da aprendizagem } \\
\text { e da reflexão }\end{array}$ & $\begin{array}{c}\text { Carona solidária, } \\
\text { encontros sociais, } \\
\text { ambiente dos plantões }\end{array}$ & $\begin{array}{c}\text { Ao longo da carreira } \\
\text { fiscal }\end{array}$ \\
\hline $\begin{array}{l}\text { Praticante } \\
\text { docente da ação }\end{array}$ & $\begin{array}{c}\text { Transferência de } \\
\text { conhecimento, de como } \\
\text { é a prática ao recepcionar } \\
\text { um novato }\end{array}$ & $\begin{array}{l}\text { Vivência de ensinar } \\
\text { enquanto age, e } \\
\text { aprender ao agir }\end{array}$ & $\begin{array}{l}\text { Os primeiros plantões de } \\
\text { um novato }\end{array}$ & $\begin{array}{l}\text { Recepção de um novato } \\
\text { no posto fiscal }\end{array}$ \\
\hline
\end{tabular}

Fonte: Autores.

Esses estágios podem ser ampliados ou fundidos, na medida em que se queiram detalhar alguns processos ou agrupá-los. Embora apresentados separadamente, os estágios, bem como os papéis neles desempenhados, se misturam, não havendo separações intransponíveis.

A iniciante pesquisa acadêmica nacional sobre o tema realça a importância deste trabalho, seus resultados e conclusões, revelando estágios do processo de aprendizagem no contexto da prática profissional. A utilização do método de história oral exemplifica sua pertinência com os estudos organizacionais. No campo da prática profissional, este trabalho pode ser utilizado como subsídio para o aprimoramento dos cursos de formação para auditores e outros afins, considerando sua tessitura científica. Ainda desta perspectiva, pode ser tomado como referência ou guia ilustrativo para aqueles auditores que individualmente queiram aprimorar seus conhecimentos.

A pesquisa permite refletir sobre o que neste estudo se denominou de teoria da prática e prática da teoria. São muitos os estudiosos que se debruçaram sobre a questão envolvendo teoria e prática; a distinção entre elas não permite compreendê-las como antagônicas, senão como complementares. Há uma busca pela teorização das coisas do mundo prático, das situações reais, não condicionadas em quaisquer esquemas teóricos ou experimentais. Pois não basta ao ser humano viver, mas é vital saber a razão do viver, a compreensão de tudo que lhe aprouver conhecer. Teoria é prática que almeja transcender-se.

Os estágios vivenciados pelos auditores fiscais estaduais em seu processo de aprendizagem revelam a necessidade de as instituições responsáveis pela sua formação empreenderem processos de aprendizagem focalizando a relação teoria-prática, com ênfase no contexto social e na relação entre a experiência e a reflexão em ação. 


\section{Referências}

ALBERTI, V. Ouvir contar: textos em história oral. Rio de Janeiro: FGV, 2007.

ANTONELLO, C.S. As formas de aprendizagem utilizadas por gestores no desenvolvimento de competências. In: ENCONTRO DA ASSOCIAÇÃO NACIONAL DE PROGRAMAS DE PÓS-GRADUAÇÃO EM ADMINISTRAÇÃO, 14. , Belo Horizonte, 2004. Anais... Belo Horizonte: Anpad, 2004.

ANTONELLO, C.S. A metamorfose da aprendizagem organizacional: uma revisão crítica. In: RUAS, R.; ANTONELLO, C.S.; BOFF, L.H. (Org.). Os novos horizontes da gestão: aprendizagem organizacional e competências. Porto Alegre: Bookman, 2005.

ARGYRIS, C. Teaching smart people how to learn. Harvard Business Review, v. 69, n. 3, p. 99-109, May/June 1991.

ARGYRIS, C.; SCHÖN, D.A. Theory in practice: increasing professional effectiveness. Tradução de Antonio Carlos Valença. 1974. (Não publicado)

ARGYRIS, C.; SCHÖN, D.A. Organization learning II: theory, method and practice. Tradução de Antonio Carlos Valença. 1996. (Não publicado)

BERGER, P.L; LUCKMANN, T. A construção social da realidade. Petrópolis: Vozes, 2008.

BITENCOURT, C.C. A gestão de competências gerenciais e a contribuição da aprendizagem organizacional. Revista de Administração de Empresas, v. 44, n. 1, p. 58-69, jan./mar. 2004.

BRETAS, A.C.P. Pesquisa qualitativa e o método da história oral: aspectos conceituais. In: Acta Paul Enf, v. 13, n. 3, p. 81-91, 2000.

CLOSS, L.Q.; ANTONELLO, C.S. o uso do método de história de vida para compreensão dos processos de aprendizagem gerencial. In: ENCONTRO ANUAL DA ASSOCIAÇÃO NACIONAL DOS PROGRAMAS DE PÓS-GRADUAÇÃO EM ADMINISTRAÇÃO - XXXII ENANPAD, Rio de Janeiro, 2008. Anais... Rio de Janeiro: 2008. 1 CD-ROM.

DEJOURS, C. Uma nova visão do sofrimento humano. In: CHANLAT, J.F. O indivíduo na organização: dimensões esquecidas. São Paulo: Atlas, 1991.

DEMO, P. Nova mídia e educação: incluir na sociedade do conhecimento. Disponível em: <www. pedrodemo.sites.uol.com.br/textos/unescomidia.html>. Acesso em: 30 nov. 2005.

DEMO, P. Teoria - para quê? Disponível em: <www.pedrodemo.sites.uol.com.br/textos.html>. Acesso em: 31 out. 2005.

DEWEY, J. A arte como experiência. São Paulo: Abril Cultural, 1974. (Os Pensadores)

DEWEY, J. Como pensamos: como se relaciona o pensamento reflexivo com o processo educativo: uma reexposição. São Paulo: Companhia Editora Nacional, 1959. 
EASTERBY-SMITH, M.; ARAÚJO, L. Aprendizagem organizacional: oportunidades e debates atuais. In: EASTERBY-SMITH, M.; BURGOYNE, J.; ARAÚJO, L. Aprendizagem organizacional e organização de aprendizagem: desenvolvimento na teoria e na prática. São Paulo: Atlas, 2001. cap. 1.

EASTERBY-SMITH, M.; BURGOYNE, J.; ARAÚJO, L. Aprendizagem organizacional e organização de aprendizagem: desenvolvimento na teoria e na prática. São Paulo: Atlas, 2001.

ENEPQ, Recife-PE, 2007. Anais... Recife: 2007. I CD-ROM.

ELKJAER, B. Em busca de uma teoria de aprendizagem social. In: EASTERBY-SMITH, M.; BURGOYNE, J.; ARAÚJO, L. Aprendizagem organizacional e organização de aprendizagem: desenvolvimento na teoria e na prática. São Paulo: Atlas, 2001. p. 100-118.

FREIRE, P. Conscientização: teoria e prática da libertação. São Paulo: Cortez e Moraes, 1979.

FREIRE, P. Pedagogia da autonomia: saberes necessários à prática educativa. São Paulo: Paz e Terra, 1996.

FREITAS, S.M. História oral: possibilidades e procedimentos. São Paulo: Humanitas, 2006.

GHERARDI, S.; NICOLINI, D.; ODELLA, F. Toward a social understanding of how people learn in organizations. Management Learning, v. 29, n. 3, p. 273-297, 1998.

GONÇALVES, R.C.; LISBOA, T.K. Sobre o método de história oral em sua modalidade história de vida. Revista Katál, Florianopólis, n. 10, n. esp., p. 83-92, 2007.

HIROTA, E.H.; LANTELME, E.M.V. Desenvolvimento de competências com aprendizagem na ação: introdução de inovações gerenciais na construção civil. In: RUAS, R.L.; ANTONELLO, C.S.; BOFF, L.H. (Org.). Os novos horizontes da gestão: aprendizagem organizacional e competências. Porto Alegre: Bookman, 2005.

ICHIKAWA, E.Y.; SANTOS, L.W. Contribuição da história oral à pesquisa organizacional. In: GODOI, C.K.; BANDEIRA-DEMELO, R.; SILVA, A.B. Pesquisa qualitativa em estudos organizacionais: paradigmas, estratégias e métodos. São Paulo: Saraiva, 2006.

KOLB, D.A. A gestão e o processo de aprendizagem. In: STARKEY, K. (Org.). Como as organizações aprendem. São Paulo: Futura, 1997.

LAVE, J.; WENGER, E. Situated learning: legitimate peripheral participation. New York: Cambridge University Press, 1991.

LINDEMAN, E.C. The meaning of adult education. New York: New Republic, 1926.

LOIOLA, E.; BASTOS, A.V.B. A produção acadêmica sobre aprendizagem organizacional no Brasil. Revista de Administração Contemporânea, v. 7, n. 3, p. 181-201, jul./set. 2003.

LUCENA, E.A. A aprendizagem profissional de gerentes-proprietários do setor de varejo de vestuário de Florianópolis. Tese (doutorado em engenharia de produção) - Centro Tecnológico, Universidade Federal de Santa Catarina, Florianópolis, 2001. 
MAIA, B. Paraíba Secretaria das Finanças: 65 anos. João Pessoa: A União, 1993.

MARSICK, V. Experience-based learning: executive learning outside the classroom. Journal of Management Development, v. 9, n. 4, p. 50-60, 1990.

MCGILL, I.; BROCKBANK, A. The action learning handbook. New York: Routledge Falmer, 2004.

MERRIAM, S.B.; CAFARELLA, R.S. Learning in adulthood: a comprehensive guide. California: Jossey Bass Inc., 1991.

MEZIROW, J. Contemporary paradigms of learning. Adult Education Quartely, v. 46, n. 3, p. 158173, Spring 1996.

MINAYO, M.C. de S. (Org.). Pesquisa social: teoria, método e criatividade. 22. ed. Petrópolis: Vozes, 2003.

MINTZBERG, H.; GOSLING, J. Educando administradores além das fronteiras. Revista de Administração de Empresas - FGV, v. 43, n. 2, p. 29-43, abr./jun. 2003.

MORIN, E. O método 3: o conhecimento do conhecimento. Porto Alegre: Sulina, 2005.

MOTTA, F.C.P.; VASCONCELOS, I.F.G. Teoria geral da administração. São Paulo: Thomson, 2004.

NOVAES, W. O povo brasileiro. Apresentação Francisco Buarque de Hollanda et al. Participação especial de Darcy Ribeiro e Washington Novaes. São Paulo: TV Cultura, GNT e Fundar, 2000. 2 DVD (120 m), son. color.

NICOLINI, A. Aprender a governar: a aprendizagem de funcionários públicos para as carreiras de Estado. Tese (doutorado em administração) — Escola de Administração, Universidade Federal da Bahia, 2007.

OLIVEIRA, M.M. Como fazer pesquisa qualitativa. Recife: Bagaço, 2005.

PARAÍBA. Lei no 8.427, de 10 de dezembro de 2007. Institui o Plano de Cargos, Carreiras e Remuneração - PCCR do Grupo Ocupacional de Servidores Fiscais Tributários — SFT do Estado da Paraíba e dá outras providências. Diário Oficial da Paraíba, Poder Legislativo, João Pessoa, no 13.681, 12 dez. 2007. p. 1.

PEREIRA, A.C.G. Em torno da mente. São Paulo: Perspectiva, 2009.

PEREZ JUNIOR, J.H. Auditoria de demonstrações contábeis. São Paulo: Atlas, 2006.

PERRENOUD, P. A prática reflexiva no ofício de professor: profissionalização e razão pedagógica. Porto Alegre: Artmed, 2002.

PRANGE, C. Aprendizagem organizacional: desesperadamente em busca de teorias? In: EASTERBYSMITH, M.; BURGOYNE, J.; ARAÚJO, L. Aprendizagem organizacional e organização de aprendizagem: desenvolvimento na teoria e na prática. São Paulo: Atlas, 2001. p. 41-63.

PRESKILL, H.; TORRES, R.T. Papel do inquérito de avaliação na criação de organizações de apren- 
dizagem. In: EASTERBY-SMITH, M.; BURGOYNE, J.; ARAÚJO, L. Aprendizagem organizacional e organização de aprendizagem: desenvolvimento na teoria e na prática. São Paulo: Atlas, 2001. p. 121-147.

REYNOLDS, M. Reflection and critical reflection in management learning. Management Learning, v. 20, n. 2, p. 183-200, 1998.

RIBEIRO, D. O povo brasileiro. Apresentação Francisco Buarque de Hollanda et al. Participação especial de Darcy Ribeiro e Washington Novaes. 2 DVD. São Paulo: TV Cultura, GNT e Fundar, 2000. 2 DVD (120 m), son. color.

ROBBINS, S.P. Comportamento organizacional. São Paulo: Pearson Prentice Hall, 2005.

ROSA, M.V.F.P.C; ARNOLDI, M.A.G.C. A entrevista na pesquisa qualitativa: mecanismos para validação dos resultados. Belo Horizonte: Autêntica, 2009.

RUAS, R. Desenvolvimento de competências gerenciais e contribuição da aprendizagem organizacional. In: FLEURY, M.T.L.; OLIVEIRA Jr., M.M. (Org.). Gestão estratégica do conhecimento: integrando aprendizagem, conhecimento e competências. São Paulo: Atlas, 2001. p. 242-269.

RUAS, R.; ANTONELLO, C.S. Repensando os referenciais analíticos em aprendizagem organizacional: uma alternativa para análise multidimensional. Revista de Administração Contemporânea, Curitiba, v. 7, n. 3, p. 203-212, 2003.

SADLER, P. Leadership and organizational learning. In: DIERKES, M. et al. Handbook of organizational learning and knowledge. New York: Oxford University Press, 2001. cap. 18, p. 415-427.

SANTOS, B.S. Introdução a uma ciência pós-moderna. Rio de janeiro: Graal, 1989.

SCHÖN, D.A. Educando o profissional reflexivo: um novo design para o ensino e a aprendizagem. Porto Alegre: Artmed, 2000.

SCHÖN, D.A. El profesional reflexivo: cómo piensan los profesionales cuando actúan. Barcelona: Paidos Ibérica, 1998.

SEIDMAN, I. Interviewing as qualitative research: a guide for researchers in education and the social sciences. 2. ed. New York: Teachers College Press, 1997.

SENGE, P. et al. Presença: propósito humano e o campo do futuro. São Paulo: Cultrix, 2007.

SENGE, P.M. O novo trabalho do líder: construindo organizações que aprendem. In: STARKEY, K. Como as organizações aprendem. São Paulo: Futura, 1997. p. 376-396.

SILVA, A.B. A vivência de conflitos entre a prática gerencial e as relações em família. 2005. Tese (doutorado em engenharia de produção) - Centro Tecnológico, Universidade Federal de Santa Catarina, Florianópolis, 2005.

SILVA, A.B. Como os gerentes aprendem. São Paulo: Saraiva, 2009. 
SIMS, R.R. Aprendizagem organizacional como desenvolvimento de histórias. In: EASTERBY-SMITH, M.; BURGOYNE, J.; ARAÚJO, L. Aprendizagem organizacional e organização de aprendizagem: desenvolvimento na teoria e na prática. São Paulo: Atlas, 2001. p. 64-80.

SMITH, P.A.C. Action learning and reflective practice in project environments that are related to leadership development. Management Learning, v. 32, n. 1, p. 31-47, 2001.

TEIXEIRA, A. A pedagogia de Dewey. In: DEWEY, J. Vida e educação. São Paulo: Melhoramentos, 1973.

THOMPSON, P. A voz do passado: história oral. Rio de Janeiro: Paz e Terra, 2002.

Antonio Soares Neto é auditor fiscal do Governo do Estado da Paraíba. E-mail: caluama@uol.com.br.

Anielson Barbosa da Silva é professor do Programa de Pós-Graduação em Administração (PPGA) e do Departamento de Administração da Universidade Federal da Paraíba (UFPB). E-mail: anielson@pq.cnpq.br. 
